\title{
ON THE SIZE-CHANGES OF DIATOMS AND THEIR OCEANOGRAPHIC SIGNIFICANCE
}

\author{
By Walter Garstang, M.A., D.Sc. \\ Emeritus Professor of Zoology (Leeds); Lincoln College, Oxford
}

(Text-figs. I-9)

The peculiar life history of diatoms-their gradual reduction in width during a series of binary fissions, and the periodic restoration of their original size after production of "auxospores"-lends itself well to biometrical treatment, and R. S. Wimpenny of Lowestoft has recently given a striking demonstration of the differences in size composition which the populations of a given species may exhibit, both seasonally and locally. His first study deals with Rhizosolenia styliformis, and by a single example he has shown that small samples of the local populations may give decisive help in tracing the origin and movements of the dense patches of this diatom which accumulate near the Dogger Bank in certain years (1936, pp. 29-60; also Savage \& Wimpenny, I936, p. 23).

This aspect of the subject, however, was not the main object of Wimpenny's study, and he did not pursue it to the full extent of his material. He noted the existence of separate "large (i.e. wide) and small (i.e. narrow) populations", as well as the prevalence of bimodal populations at one time and of unimodal populations at another, but his main concern was an attempt to relate changes in average width to physical conditions. He claims that, in spite of the normal tendency of the diatoms to decrease in width as a consequence of repeated fission, the average width of the population tends to increase ("in each year", p. 38) during periods of rising temperature, or during periods of drift from regions of lower to regions of higher temperature. To account for this supposed relation he has recourse to a theory of selection, increase of temperature being held to favour survival of the wider diatoms.

This complex proposition is put forward quite tentatively, but is believed to be in harmony with the distribution of wide and narrow diatoms in warm and cold areas generally, a separate question which I have not examined. But the special propositions advanced with regard to Rhizosolenia are soon seen to have no adequate basis. The alleged correlation between average size and temperature breaks down at several points when the probable errors are taken into account, and the valid coincidences admit of much simpler explanations. In a region of intrusive and eddying waters, Wimpenny disregards the inevitable mixture of local populations, and most unaccountably, although he admits the upper size group in his bimodal samples to be the recent product of an auxo- 
spore generation, the rise of this generation is overlooked, and the resultant increases of size are included among his evidences of "selective survival". So far from there being a seasonal tendency towards increase of size, his samples show that in the main area of his investigations the size went up steadily during the summer of 1933 after an auxospore rejuvenation (though auxospores were not directly observed), and steadily down throughout 1934, during the succeeding phase of repeated fission. The failure to observe auxospores in either of the three years (p. 40) may be attributable to the fact that during the most favourable period, from mid-July to mid-September, no samples were taken.

It is, in fact, the regularity of the life cycle, its long duration (at least two, possibly three years), and its contrasted phases, which render the biometry of diatoms so admirably suited to oceanographic ends, and I believe Wimpenny's introduction of it in planktonic study may lead to fruitful developments. With due precautions the measurement of diatoms may yield precise indications of water conditions, water movements, and water mixture. In this belief I venture to submit a brief alternative treatment of Wimpenny's data, not so much to establish any particular propositions, as to indicate what kinds of problem may be brought to solution by the examination of samples suitably distributed.

Wimpenny's samples, twenty-two in number, were nearly all obtained by vertical hauls in the more or less dense "patches" already described for 1932 by Savage \& Hardy (1935, pp. 3I-4) and for I933-4 by Savage \& Wimpenny (I936). They are mostly limited to Ioo specimens from each station except in 1933, when half the samples were increased to 300 . The curves show that when the population is homogeneous the lower number is fairly representative, but when it consists of two generations, or of a mixture of two populations with different modes, the jagged nature of the curves shows this number to be inadequate for comparative purposes. In future work the standard sample should consist of not less than 200 individuals.

At one station (K I2), off the Outer Dowsing in October 1933, there is a check on the reliability of a sample in the fact that a horizontal haul at midwater (Io m.) was sampled as well as a vertical haul, and roo measurements are recorded for each. Both curves have the same mode (at 20 units) with practically the same frequency $(24,25 \%)$, but the vertical sample has a "shoulder" on the lower side of the mode (at 17), and the horizontal one a larger shoulder on the upper side (at $22-23$ ), so that the average width is appreciably less for the former than for the latter (I8.96 as against 20.16 - calculated from Table II, p. 56). Wimpenny gives the average width for the station as I9.00 (p. 38), but as he denies the existence of any "marked differences of size" at different depths in the Southern Bight (p. 37), the variation revealed in two samples of a fairly homogeneous population shows the necessity of allowing an appreciable margin of error for the average size of the samples generally. The question, however, of a possible stratification in the vertical distribution of the different sizes ought not to be left without evidence. 
In the summary account which follows I have retained Wimpenny's size units, which are stated to be approximately equal to $4 \mu$. The curves for all the samples have first been drawn separately, but when two or more curves for the same time and area show the same essential features, I have here substituted a single representative curve based on a combination of the samples, so as to eliminate the greater irregularities due to small numbers. In two cases only (I933, F 5, VII; J 5, Ix), where combination was impossible, erratic single curves have been smoothed. All the curves of size are percentage curves. The three years are dealt with separately, and in each year the curves for the same region are superimposed, so as to bring out more easily the seasonal changes shown by the samples.

\section{2}

Three samples were measured in October from a dense patch south of the Dogger, the positions and movements of which are fully described by Savage \& Hardy (I935, figs. I9-2I). Its western edge was located on October I4 30 miles south of the South-west Spit of the Dogger, and in a fortnight had moved 50 miles east, with its axis extended north-east for an additional 70 miles at least. The samples came from three stations, 60 miles apart, along this track, say $A, B$, and $C$ from west to east, the sample from $A$ (Wimpenny's H.Q.) being a fortnight earlier than those from $B(\mathrm{~J} 26)$ and $C(\mathrm{~J} 20)$. The erratic curves of size are given separately by Wimpenny, but $A$ and $B$ differ from $C$ in being essentially bimodal, with their main features in common, so in my treatment these two have been combined (Fig. I).

The average widths of the three samples are given by Wimpenny as $15 \cdot 3$, $\mathrm{I} 6.0$, and $\mathrm{I} 6.8$; the temperatures as $\mathrm{I} 2 \cdot 23^{\circ}, \mathrm{I} 2 \cdot 24^{\circ}$, and $\mathrm{I} 2.44^{\circ}$ respectively. This "progression of the means", in connexion with the "advance" of temperature, is specially cited by Wimpenny as one of his chief examples of selective survival ("this apparent selection of the wider cells as the patch drifted into areas of higher temperature", p. 40). The curves, however, contain clear evidence, not of selection, but of a progressive mixture of two divergent populations, a bimodal population $(X)$, strongest in the west, with a major mode at $12-13$, a minor mode at $19-22$, and a trough at $17-18$, and a unimodal population $(Y)$, strongest in the east, with a mode about I7. This size is scarcely represented in $A$, but forms a shoulder on the upper side of the major mode in $B$, and the principal peak in $C$. Minor differences between the curves for $A$ and $B$ suggest that neither of the primary populations was quite constant from west to east, particularly the unimodal one, which at $A$ probably had its peak at I5 or I6 as indicated by the lower position of the shoulder (at I6 instead of I7) and by the wider "trough" (at I7-I8 instead of I8).

A rough attempt to reconstruct the observed populations by mixture of two hypothetical primaries is represented in Figs. 2 and 3. $X$ and $Y$ are two possible "primaries", $X$ being bimodal and for simplicity assumed to have been uniform throughout, $Y$ being unimodal and assumed to be represented 
in the west $(A)$ by a similar population with its mode one unit lower $\left(Y^{\prime}\right)$. A 2: I mixture of the two primaries, with $X$ predominant at $A$ and $B$,

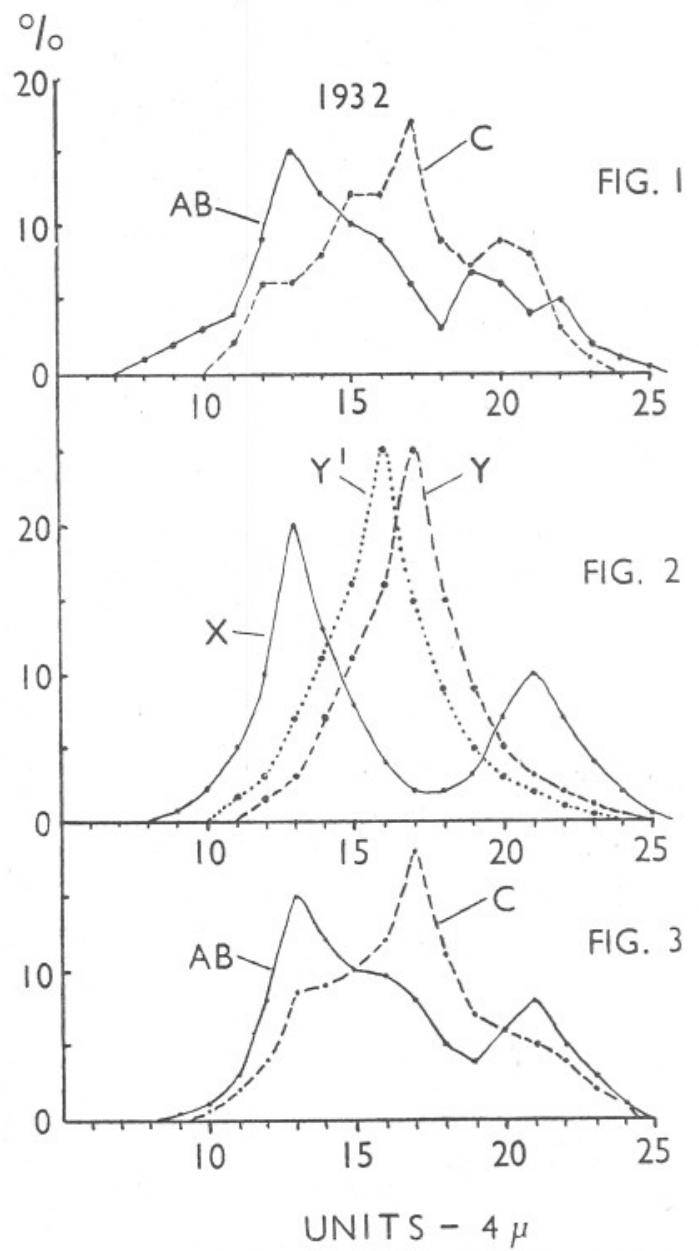

Fig. r. Frequency curves of variation in width of Rhizosolenia styliformis at stations $A+B$ (combined) and $C$ in October (percentages). $A B=$ Wimpenny's H.Q. + J 26. $C=$ Wimpenny's J 20.

Fig. 2. Hypothetical pure populations supposed to be mixed in Fig. I.

Fig. 3. Empirical mixtures of $X$ with $Y^{\prime}$ (west) and $Y$ (east). $A B=\left(2 X+Y^{\prime}\right)+(2 X+Y)$. $C=X+2 Y$.

and $Y$ predominant at $C$, may then be expressed by the following combinations:

$$
\begin{aligned}
& A=2 X+Y^{\prime}, \\
& B=2 X+Y \text { or, more closely, } 2 X+\frac{Y^{\prime}+Y}{2}, \\
& C=X+2 Y,
\end{aligned}
$$


or, combining the formulae for $A$ and $B$, in conformity with Fig. I,

$$
\begin{aligned}
A+B & =4 X+Y^{\prime}+Y, \\
C & =X+2 Y .
\end{aligned}
$$

The results of the last two combinations, after reduction to percentages, are seen in Fig. 3, and should be compared with Fig. I. It will be admitted, I think, that this empirical synthesis comes sufficiently near the mark to justify my interpretation of the populations sampled as mixtures of two purer populations of the $X$ and $Y$ type in something like the proportions given.

There are unfortunately no available data outside the patch to show the source or distribution of the two populations of which it appears to be compounded, although specimens collected by Prof. Hardy's continuous recorders during September and October would probably fill the gap if measured (cf. Savage \& Hardy, I935, fig. 2I). The different constitution of its eastern "head" and western "tail" seems to indicate that it was formed either (I) by the fusion of two separate patches, ultimately east and west, or (2) along a line of convergence of northern and southern waters, which brought successive northern and southern populations into contact and mixture. The coexistence of two divergent populations, but without serious mixture, was a striking feature of the samples in October I933. In the following autumn (1934) we shall see that mixed populations were again conspicuous on the central grounds, but this time in the same phase with nearly related modes at I5 and 17.

I933

In I933 there are samples for July, September and October off the western edge of the Dogger, two October samples from the Bank itself, and eight October and November samples from a wide area south of it. The last series is so uniform that the samples have been united to form two large arrays representative of the two months. The curves (Figs. 4-6) for the three areas follow the order here given, those for each area being superimposed.

In the first area two of the samples (F 5, vII; J 5, Ix) are small (I00), yielding very jagged curves, which would be confusing if superimposed. I have therefore smoothed them by readjustment of the frequencies as follows:

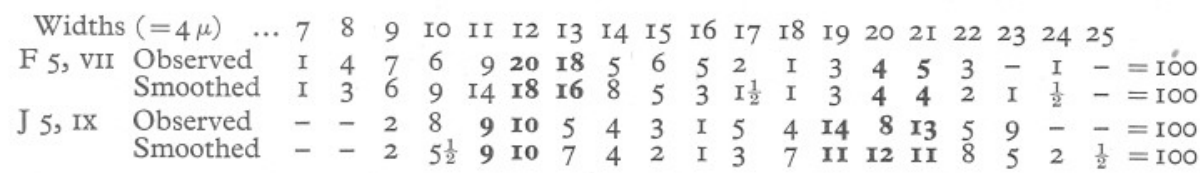

The third sample ( $\mathrm{L}_{30}, \mathrm{x}$ ) was larger (300). Its curve (and that of every other sample, or combination of samples, in this account) is unsmoothed.

All the curves for this year show a pronounced bimodality, as Wimpenny (p. 32) observed. The two groups are here assumed to mark successive auxospore generations, the old generation having a mode at II-I2, the new one at 


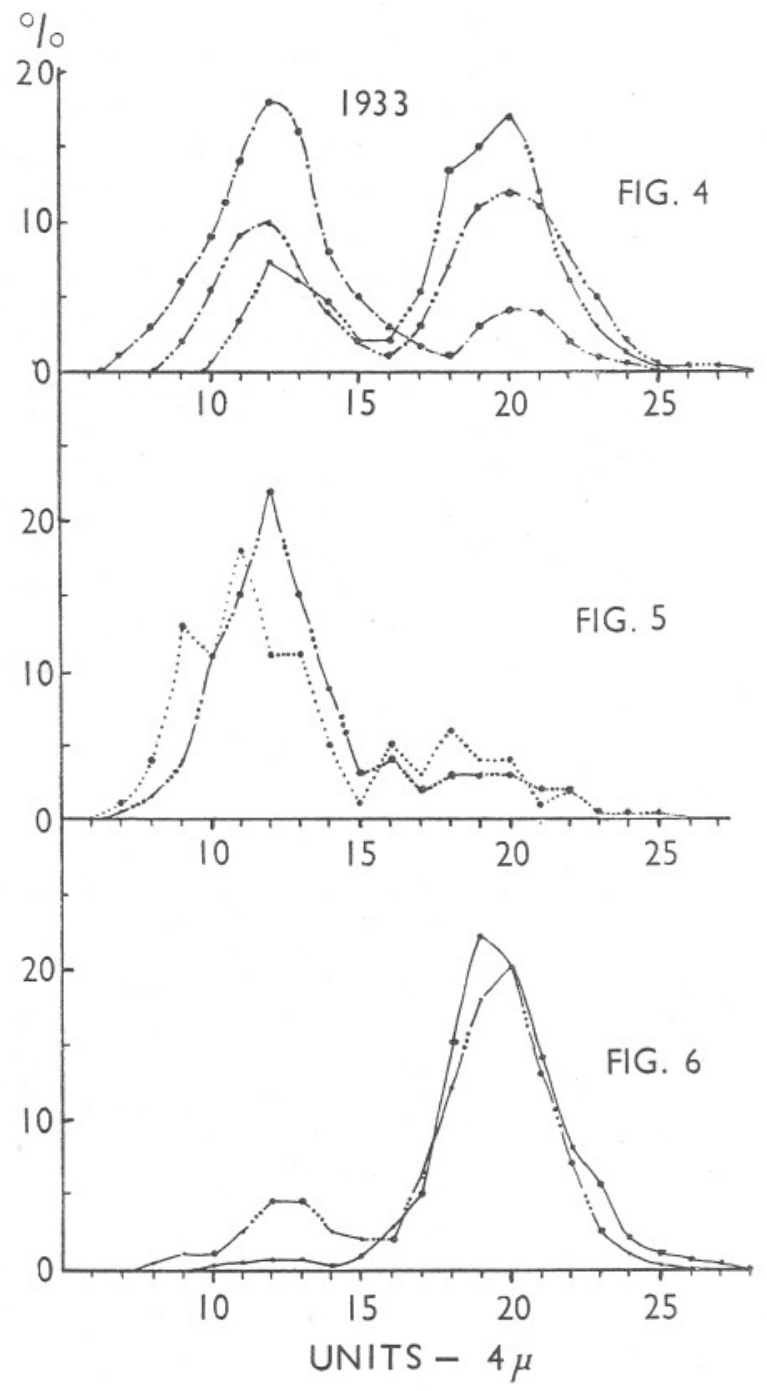

Fig. 4. West of Dogger. July (F 5), - - - - - Sept. (J 5), - - - - - - , both smoothed. October (L 30 ), unsmoothed, - - . - …-

Fig. 5. Dogger Bank, October. Combined samples (K $28+\mathrm{L} 35),-\cdots-\cdots-$. K 28 alone, $\cdots \cdots \cdots$. .

Fig. 6. Coastal belt, South of Dogger. October, five samples combined, $-\cdots-\cdots-$. November, three samples combined, - 
I9-2I. There is a difference of phase, but not of type, between the curves of the first and third areas, and, as the first includes the earliest samples (VII, IX, $\mathrm{x}$ ), and the third the latest (x, xI), the two together illustrate all the stages in the waning of an old generation and the rising of a new one. In July (F 5) the old generation far exceeded the new one in frequency, in September ( $\mathrm{J} 5$ ) the new generation had slightly out-topped the old one, and by October the old and new generations had everywhere changed places as regards frequency.

The two curves for the third (or southern) area (Fig. 6) have been yielded by combinations of the following samples; duly weighted:

October: K I (I00), K I2 (200), K I3 (100), L 9 (300), L I5 (300).

November: "Onaway", 8 (I00), 9 (300), and "Tea Kettle Hole" (I00).

Fig. 6 shows how completely the old generation had been replaced in November by the new one, and that the mode of the latter had already receded from 20 to I9, doubtless as a consequence of repeated fissions.

The second or Dogger group (Fig. 5) consists of two samples only, both from dense October patches on opposite sides of the Bank, viz. K 28 (Io0) and L 35 (300). The former yields a jagged curve, and has been combined with the other to form a single representative curve, but it has also been added to the figure as an indication of the slight differences involved, its mode being a unit lower than that of the other. Geographically the three samples from the first area especially $\mathrm{L}_{30}$, are barely distinguishable from the Dogger samples, being only 20 or 30 miles south or south-west of $\mathrm{K} 28$; but, as shown by the curves, the October populations of the two areas were very different, the new generation on the Dogger being no further developed than it was in July in the western group, and its principal, or old, generation having the same mode (I2), in spite of intense proliferation. The question of divergent populations in close proximity is thus raised again in a new form: Are we to regard the October phase on the Dogger as merely the July population retarded in development, or as an alien population from some other region?

$\mathrm{K} 28$ was taken near the south-west edge of the Dogger shoal a fortnight before $\mathrm{L} 35$, the position of the latter station being 50 miles farther east, off the south-east edge of the Bank. Savage \& Wimpenny give hydrographic reasons for regarding the two stations as representing successive centres of the same patch, which they believe had rounded the southern extremity of the Bank in the meantime. If the mode of $\mathrm{K} 28$, however, can be relied upon, as seems probable, this view is in opposition to the biometric evidence, since $\mathrm{K} 28$ was in a later, not an earlier, phase of size reduction. The conditions, in fact, partially reproduce those of the patch of 1932 , but without the complexity of a mixture of populations, $\mathrm{K} 28$ recalling $A$, and $\mathrm{L} 35$ recalling $B$ or $C$, in which the mode of the $Y$ population was higher than it was at $A$, and therefore not directly derivable from it. In this case also the eastern and later patch ( $\mathrm{L}$ 35, October 22) cannot be regarded simply as the western patch ( $\mathrm{K} 28$, October I3) which had shifted its position. If $\mathrm{K} 28$ was its nucleus, it must 
have picked up a great preponderance of other diatoms with the higher mode in transit. More probably an eastern patch was already in existence at the time of the $\mathrm{K}$ cruise, but just beyond its range (cf. Savage \& Wimpenny, figs. 2 and 4), and was joined by the western patch during the intervening fortnight. Hardy's recorder sampled two strong patches on the Hull-Skagerak line, along the south-east edge of the Dogger, on October I4, thus supporting this suggestion. One may remark again how useful it would be to have their measurements (Hardy, I935, fig. 4).

As regards their origin, the patches may have been formed within successive swirls off the Dogger Bight, but, in view of their great density (over 500,000 per $\mathrm{m}^{3}{ }^{3}$ ) it is impossible to identify them with the similar population found on the South-west Spit (F 5) in July. To allow for their subsequent proliferation, their modes in July must have been at least two units higher (cf. the seasonal changes in the mode during 1934 below), so that the hypothesis of a different origin is probable. They may, in fact, have been descendants of the same stock which contributed the $Y$ element to the patch of I932, though there is nothing but the calculated correspondence of their modes to support the suggestion. In both cases this stock and its descendants were presumably of northern origin.

Similarly, the $X$ element of 1932 , with its new generation still rudimentary in October, may have been part of a western population which survived to initiate the great bimodal population west and south of the Dogger in 1933 .

\section{I934}

For 1934 the samples (all 100) also fall into three groups, but not quite the same as for 1933: (I) the North-west Deeps (Firth of Forth Swirl), (2) the Dogger region, and (3) the coastal belt, the last with only two stations, G 5 off Flamborough Head in July, and M 2I, 50 miles north-west of Texel in October.

The first group (Fig. 7) is especially interesting, since it throws light on conditions in a region farther north than was sampled in 1932 and 1933 . Two samples (C I9, V and E 5, VI), with modes at IO and II respectively, have been combined to represent the spring condition. A third ( $\left.\mathrm{M}_{3}\right)$ was taken in October. The increase in average width (I0.94 in May, 12.50 in October) is included by Wimpenny among his examples of increase of size with temperature. The spring population, however, was unimodal, and consisted of old generation diatoms only; the autumn population was bimodal, with two cusps of almost equal frequencies at 7 and I6. These modes are lower than those of the bimodal populations farther south in 1933, but the interval is the same. They clearly mark a new generation in the making.

Comparison with Figs. 8 and 9 shows how completely this area differed from the whole of the southern region in its population phase at any time, thus showing, as Wimpenny pointed out, that the Rhizosolenia patch that was forming off the western edge of the Dogger in June (E I7) could not possibly 


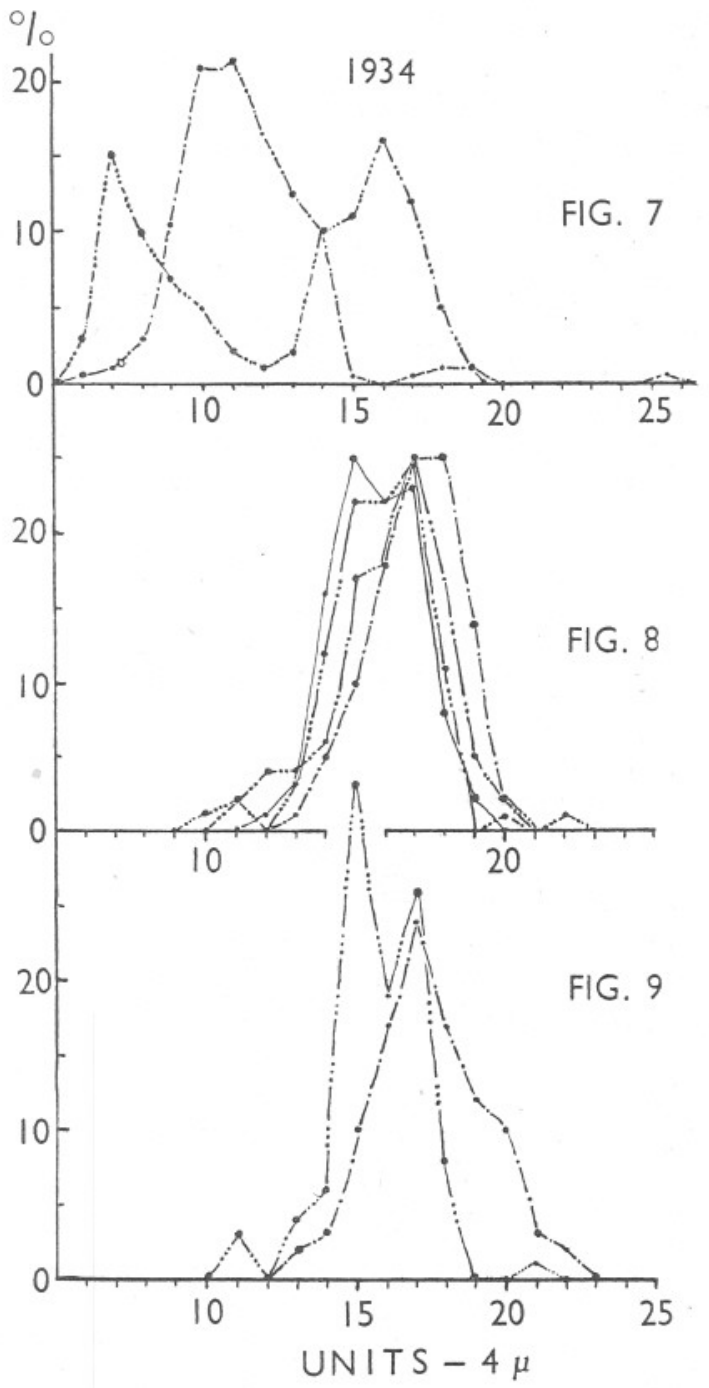

7. North-west Deeps (Firth of Forth Swirl). May (C I9) and June(E 5) combined,- - - - - . 8ctober (M 3), Dogger Bank. June (E I7), - - - . Sept. (L I7), - - - - Oct. (M I4), - -.- - Nov. 8. Dogger Bank. June (E I7), - - Sept. (L I7), - - - . Oct. (M 14), 9. Coastal belt. July (G 5), off Flamborough, - - - - - October ( $\mathrm{M} 2 \mathrm{I}$ ), North-west of Texel, - . - . . . 
be an offshoot from the northern population (E 5) (Savage \& Wimpenny, I936, p. 23).

Nevertheless, the two regions are probably not completely independent. The mode of the northern population in the spring (IO-II) closely recalls that of the Dogger patch of the previous October (II-I2), and the difference is no greater than can reasonably be attributed to the effect of successive fissions in the interval. As this Dogger population completely disappeared from the Bank during the winter (cf. Fig. 8), it was probably carried away to the north, and may well have been brought round to the Forth region in the wide anticlockwise circulation north of the Bank. Such a circuit might account for the irregularity shown by the two spring modes, that of the earlier sample (C I9) being actually a unit lower than that of the later one (E 5). Both curves also show a hump at I4, which betrays appreciable mixture with some unknown alien population.

The second and third groups show so much in common that they may be considered together. The second (Fig. 8) includes the following samples:

$\begin{array}{llll}\text { June } & \text { E } & \text { I7 } & \text { Mode 17-I8. } \\ \text { Sept. } & \text { L } & \text { I7 } & \text { Mode I7, with "shoulder" at I5. } \\ \text { Oct. } & \text { M I4 } & \text { Mode 17, with stronger shoulder at I5. } \\ \text { Nov. } & \text { On. } 6 & \text { Mode 15, with shoulder at I7. }\end{array}$

All four stations were on, or near, the southern shoal of the Dogger.

The third group includes:

July G 5 Mode $\mathrm{I} 7$, with low shoulder at 19-20.

Oct. $\quad M_{21}$ Mode I5, with minor peak at I7.

The July station was off Flamborough Head, 30 miles from the South-west Dogger; the other was 50 miles south-east of the southern edge of the Dogger, half-way to Texel.

The September and all later samples show signs of extensive mixture between two nearly related populations with modes at I5 and I7 respectively. A study of the curves and of Savage \& Wimpenny's charts leaves little doubt as to their history, although an additional sample or two from the southern belt would have been welcome. The mode at $\mathrm{I} 7$ was especially characteristic of the Dogger samples, that at I 5 of the single southern station. In the former the shoulder at I5, rising steadily through September and October, ultimately in November surpassed the original mode in frequency. From its omission of the intermediate mode at I6 this change cannot have been the result of local proliferation, but marks an intrusive element. In September Savage \& Wimpenny (I936, fig. I4) defined a great reniform patch pivoted on the south-west part of the Dogger and expanded southwards over a large area of the Norfolk banks, with two centres of density, a small one on the Dogger with a density maximum of 100,000 per m. ${ }^{3}$, and a large one over the Norfolk banks with a maximum density of 300,000 per m. ${ }^{3}$ The patch arose by the fusion in July of two separate light patches which had apparently formed successively in the 
Dogger Bight in June and been arrested in their movement eastwards (loc. cit., figs. IO-I2). The original population of both was probably identical, or nearly so (cf. E I7, G 5), but the greater rate of proliferation over the Norfolk banks already indicated would reduce the mode more rapidly in the southern patch, while in August-September the marked conditions of swirl (loc.cit., figs. I3, I4) which followed their fusion would induce the observed mixture of the two populations. This would be more marked in the Dogger samples because of the greater density of the southern portion of the patch. In October the patch broke up again, or became highly ramified, and the larger southern portion drifted eastwards. M 2 I sampled the western side of the drifted patch in October; L I7 sampled the northern centre of density of the united patch, M I4 and On. 6 the same part after the southern mass had separated.

The modes of the two spring samples (E I7 and G 5) at I7-I8 seem clearly to affiliate both these populations to the autumn stock on the coastal belt in the previous year $(M=19-20)$. Savage \& Wimpenny (1936, p. 25) have already attributed the wide distribution of this diatom in 1934 to the "scattering by water movements during the intervening months of the residue following the big flowering which took place in the autumn of 1933". It should be noted, however, as already remarked, that the dense patches on the edge of the Dogger in that year contributed practically nothing to the initial populations of 1934, either on the Dogger itself, or on the coastal banks. They must have been swept completely out of the region during the winter.

The sharp contrast between the Dogger and coastal modes in 1933, and the wide range of intermixture of less divergent populations in 1934 imply a considerable difference in the current systems of the two years, which Savage \& Wimpenny have set out in great detail. The main difference between the two years, however, seems to be brought out more simply by the populations of Rhizosolenia. In 1933 the presence of a distinct northern population on the Dogger may be associated with the early invasion of saline northern water over the Bank, its prolonged duration there, and the pressure it set up against intrusion from the coastal waters, while in 1934 there was no such influx after July, consequently no northern population, and no resistance against encroachment. The Dogger and Norfolk banks were populated alike from the west, and early differences in the mode, caused by different rates of proliferation, were soon swamped by intermixture.

\section{Summary of Population Changes, 1932-4}

In the following table an attempt has been made to summarize the preceding survey by picking out the spring and autumn characters of the Rhizosolenia populations for each of the three main areas in each of the three years, and by bracketing together those populations which appear to have been connected by direct descent.

A thick inverted $\mathrm{V}$ indicates a normal unimodal population $(\Lambda)$, the mode 
of which is given alongside in Wimpenny's units $(=4 \mu)$. A thick inverted W marks a bimodal population (M), i.e. an old generation with low mode, and a new generation with high mode. A fraction preceding the letter $R$ indicates roughly the amount of Regeneration which has taken place. Thus, $M \frac{1}{4} R$ means a bimodal population in which the old generation still greatly preponderates; $M \frac{1}{2} R$, one in which the old and new generations are approximately equal; $M \frac{3}{4} R$, one in which the new generation preponderates, and the old generation is more or less obsolete. $\mathrm{Mm}=$ major mode.

\begin{tabular}{|c|c|c|c|}
\hline \multicolumn{2}{|c|}{$\begin{array}{l}\text { North-west Deeps } \\
\text { (Firth of Forth Swirl) }\end{array}$} & Dogger Bank & $\begin{array}{l}\text { South an } \\
\text { (coastal } \mathrm{b}\end{array}$ \\
\hline $\begin{array}{l}\text { I932, } \mathrm{x} \\
\text { I933, v-VI } \\
\text { I933, } \mathrm{x}-\mathrm{XI}\end{array}$ & $\begin{array}{l}? \\
?\end{array}$ & $\begin{array}{l}\wedge \mathrm{M}=\mathrm{I} 6-\mathrm{I} 7 \\
-\mathrm{M} \frac{1}{4} \mathrm{R}, \stackrel{?}{\mathrm{Mm}}=\mathrm{II}-\mathrm{I} 2\end{array}$ & 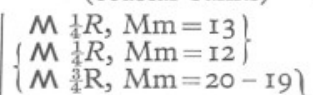 \\
\hline $\begin{array}{l}\text { I934, V-VI } \\
\text { I934, } \mathrm{x}-\mathrm{XI}\end{array}$ & $\left\{\begin{array}{c}\hat{M}=\mathrm{II}-\mathrm{IO} \\
\mathrm{M} \frac{1}{2} R, \mathrm{M}=7+\mathrm{I} 6\end{array}\right.$ & $\left.\begin{array}{l}\hat{M}=\mathrm{I} 8-\mathrm{I} 7 \\
\wedge \mathrm{M}=\mathrm{I} 7(-\mathrm{I} 5)\end{array}\right\}$ & $\left\{\begin{array}{l}\hat{M}=\mathrm{I} 7(\mathrm{vII}) \\
\wedge \mathrm{M}=\mathrm{I} 5\end{array}\right.$ \\
\hline
\end{tabular}

It will be noticed that the population on the coastal banks seems to have been uninterruptedly continued from one season to another without any sign of marked invasions from without. Starting in October 1932 with a bimodal population in which rejuvenation had only recently begun, and the mode of the old generation stood at 13 , the whole life cycle was still incomplete in November 1934, when the mode was 15. Assuming that it was completed in the spring of 1935 it required $2 \frac{1}{2}$ years for its accomplishment. If we regard the coastal population accordingly as indigenous and self-maintained, although perpetually being carried away by the north-easterly drift, its annual renovation must depend on the persistence in the west of adequate residues of the previous year's stock.

On the Dogger Bank the population seems to have been continuous from October 1932 to November 1933, and during this period to have been quite independent of the stock on the coastal banks. A complete break then followed, and the new population in the spring of 1934 was indistinguishable at first from that on the coastal banks. A slight difference seems to have developed later, owing to local differences in the rate of proliferation, but from September onwards, as we have seen, there was incessant intermixture.

The fragmentary data for the North-west region are limited to the last year, which is unfortunate. In the spring of 1934 the initial stock, though slightly mixed with some other population, was closely similar to the Dogger population of the previous autumn. The chief difference between the two strains is that the Dogger population was already showing the beginnings of a new generation in 1933 (Fig. 5), while that of the North-west Deeps, though showing vestiges of such a start, did not enter upon this phase with any vigour until after June I934. If, as suggested, the North-west population was largely descended from the previous Dogger stock, the intervening winter, and a prolonged northern circuit, must have completely checked regeneration by auxospores, and a further period of proliferation must be assumed to have set in to account for the reduction of the mode from II-I2 to IO-II. We know 
that this proliferation actually took place (Savage \& Wimpenny, 1936, p. II, fig. 9). It is also very noticeable that, after rejuvenation was resumed, both modes of the resultant population were markedly lower than at the corresponding phase on the coastal banks during 1933. This reduction may have been a further consequence of the enforced stoppage of rejuvenation during the winter and the additional proliferation which ensued before the season of auxospore formation had arrived. It may, on the other hand, though improbably, mark a permanent racial difference, which only additional observations can settle.

Further investigations in this area are clearly desirable in order to correlate with conditions on the Dogger. It seems highly probable that in "Atlantic" years, when northern waters extend southwards over the bank, a close relation will be recognizable between the population phases of the Dogger and of the North-west Deeps.

But it would perhaps be as well before detailed observations are made that the biology of $R$. styliformis should be more closely studied. It is, for instance, not known to what extent or at what times resting spores are formed, or whether diatoms arising from resting spores begin at the same size as those from which the spores were formed. If they were of different size the wrong conclusion that they had been transported from elsewhere might result. In any case I hope to have shown that with sufficient knowledge of the biology of Rhizosolenia the start made by Wimpenny on measurements of diatoms may lead to the foundation of useful indicators of water movements. In the open ocean also, where mixture may be less troublesome than in the North Sea, the proof of a long and well-marked life cycle in Rhizosolenia may ultimately yield a valuable timetable in problems of water transport.

\section{SUMMARY}

Wimpenny's measurements of Rhizosolenia styliformis (this fournal, Vol. xxI, pp. 29-60, 1936) are used to discuss the value of population curves of this species as indicators of water movements and mixture in the North Sea. His alleged correlation between average size and temperature is shown in this case to be untenable. On the coastal banks during 1933 there was a steady increase of size accompanying normal regeneration (bimodal curves), but this was complete by November, and in 1934, with fuller seasonal sampling, the size steadily diminished (all curves unimodal). The population phases on the Dogger and coastal banks were markedly divergent in 1933, but almost identical and intermixed in 1934, indicating a northern ("Atlantic") influx in I933 and its absence in I934. Off the southern edge of the Dogger in the autumn of 1932 a bimodal and unimodal population were variously mixed, the former showing relations to the coastal population of the following spring, the latter probably marking the intrusive northern element which persisted into 1933. The spring population of 1934 in the Firth of Forth Swirl (as already 
noted by Wimpenny) was quite different from that farther south, both Dogger and coastal, the northern influx having then disappeared, but it showed significant relations to the Dogger population of the previous autumn.

\section{REFERENCES}

Hardy, A. C., I935. The continuous plankton recorder. Rapp. Proc. Verb. Cons. Int. Expl. Mer., Vol. xuv, p. 39.

Savage, R. E. \& Hardy, A. C., I935. Phytoplankton and the herring. Part I, I92 I-32. Min. Agric. Fish., Fish. Invest., Ser. II, Vol. xIv, No. 2.

Savage, R. E. \& Wimpenny, R. S., I936. Phytoplankton and the herring. Part II, I933 and I934. Min. Agric. Fish., Fish. Invest., Ser. II, Vol. xv, No. I.

WIMPENNY, R. S., I936. The size of diatoms. I. The diameter variation of Rhizosolenia styliformis Brightw. and $R$. alata Brightw. in particular and of pelagic marine diatoms in general. Fourn. Mar. Biol. Assoc., Vol. xxI, pp. 29-60. 